\title{
Environmental sustainability of Russian regions: energy and carbon intensity of regional economy
}

\author{
VM Zhigalov ${ }^{1, *}$ \\ ${ }^{1}$ Saint Petersburg State University, Universitetskaya embankment, 7/9, Saint-Petersburg, Russia
}

\begin{abstract}
The article deals with one of the main elements of strategic sustainability of Russian regions environmental and energy sustainability. The author proves the interrelation of energy and pollution intensity of regional economy. The article presents results of the factors analysis affecting the changes in energy and pollution intensity of GRP. The study allowed to draw conclusions about the most important factors to be taken into account in the formation of environmental and energy policy in regions. In addition, the article provides recommendations for the strategy of sustainable development in the regions of Russia.
\end{abstract}

\section{Introduction}

Regional sustainability is one of the most important goals of socio-economic development in Russia. The past periods of economic recession in 2008 and 2014 demonstrated a considerable decrease of key indicators of socio-economic development as a result of development imbalance. In addition, a significant number of regions of Russia can be attribut ed to the group of depressed (their indicators are at a consistently low level for an extended period of time) [9], among which, according to the results of various studies, the Pskov Region [7]. Therefore, the achievement of strategic sustainability at the regional level is among the priorities of socio-economic development in Russia.

Sustainability of regions is directly related to the sustainability of regional enterprises. Studies show a direct correlation between economic, social, innovation and other indicators of the enterprises sustainability in the region and indicators of the socio-economic development of the region [18]. Environmental indicators, which should be taken into account when assessing the strategic sustainability index of enterprises in the region, are no exception [8]. The interrelation of enterprises and regions indicators is natural, since many regional indicators are calculated on the basis of data and reports of enterprises, which, in particular, relates to indicators of pollutant emissions, energy consumption and other components of environmental sustainability.

The difference in the level of regions sustainability is explained, on the one hand, by exogenous factors that are difficult to manage, and, on the other hand, by endogenous factors that should be taken into account in the strategy of sustainable development of regions. In the context of environmental sustainability exogenous factors include climatic, territorial and other factors, the endogenous factors include the structure of the economy, the level of innovative development, the quality of the technologies, the quality of management, etc. As a result of Russia's signing of the framework convention on climate change at the climate conference in Paris [1], the important aspect of environmental sustainability is the reduction of climate impact. This objective should be set also at regional level, thus the key instruments of Paris agreement are energy efficiency increase and greenhouse gases emissions (carbon intensity) decrease. The main indicator of the energy efficiency of the regional economy is the energy intensity of GRP - the ratio of consumed energy to the produced GRP (calculated by the Federal state statistics service of the Russian Federation). Carbon intensity of the regional economy is calculated as the ratio of greenhouse gas emissions to GRP. Statistics of greenhouse gas emissions in the Russian regions is currently just beginning to form, so in this study carbon intensity of the economy is replaced by an indicator of the pollution intensity - the ratio of major pollutants emissions to GRP (this indicator is estimated in the report "Environment condition and protection in the Russian Federation" of the Ministry of natural resources and environment [16]).

Contemporary studies cover different aspects of environmental sustainability at regional level: methodology of enterprises and regions sustainability evaluation [10], problems of unequal regions development [15], transition to alternative energy as an important condition of environmental and energy security and sustainability of the country and its regions [12]. The complex studies analyze the impact of the regional economy structure on its energy intensity [11], calculate the energy load on the regional environmental system [3] and develop forecasts of energy and petroleum consumption by road transport, taking into account the prospects for transition to alternative sources [5]. Approbation of various models for analyzing factors affecting the greenhouse gas emissions dynamics is also the focus of attention [13].

\footnotetext{
Corresponding author: v.zhigalov@spbu.ru
} 


\section{Methods}

The study was based on economic and mathematical methods, including econometrics. The author also based his recommendations on comparative analysis methods, new concepts of public administration, including New Public Management and Governance concepts, and performance management approach, which were adapted to the problems of improving energy efficiency and reducing the impact on the climate.

The energy intensity of GRP and the pollution intensity of GRP in the regions of Russia are interrelated, which can be justified by the following manipulations (see [17] for the details):

$$
\begin{aligned}
& \text { Pollution intensity }=\frac{\text { Pollution }}{G R P}= \\
& =\frac{\text { Pollution }}{\text { Enetgy }} \times \frac{\text { Pollution }}{G R P}=\frac{\text { Pollution }}{\text { Enetgy }} \times \text { Energy intensity }
\end{aligned}
$$

Thus, the pollution intensity is determined, firstly, by the level of energy intensity of GRP, and secondly, how "dirty" this energy is consumed. In this regard, to determine the strategic goals in the sphere of regional environmental sustainability, it is necessary to consider the most important factors affecting these indicators.

To assess the factors affecting the level of energy intensity of the economy and the level of "cleanness" of energy consumption in the regions of Russia, the author used a variety of indicators, including indicators of the economy structure of the regions, climate indicators (average air temperature), technological indicators (for example, the share of innovative product in the structure of GRP), spatial (area), the level of urbanization (the proportion of urban population) and a number of others. The hypothesis about the structure of factors was based on similar studies conducted at the level of countries (see, for example: [6]; [4]). The main source of data was the Federal state statistics service (Rosstat). All subjects of the Russian Federation were included in the analysis, with the exception of Autonomous districts, as well as the Republic of Crimea and Sevastopol due to inaccuracies and limitations of available data. The study evaluated a model with fixed effects (both by region and by year). The evaluation was carried out in the Stata 14.1 package. This study is presented in detail in one of the author's previous work [17].

\section{Research and results}

As a result of the study, the following variables showed a stable correlation with changes in the energy intensity of GRP in the Russian regions: the share of transport in GRP, the average temperature in January of atmospheric air and land area. The contribution of other variables that were previously identified as hypothetically important was insignificant. The results of the structural factors analysis deserve special attention. In particular, the share mining industry in GRP, as well as for metallurgical industry, which are one of the most energy-intensive sectors of the economy, do not have a significant impact on the change in the energy intensity of regions GRP.
Since the energy intensity of GRP is the main indicator of the energy efficiency, this indicator is influenced not so much by the level of energy costs as by the return on the energy resources use. According to the official data of the Federal tax service, the most profitable type of economic activity in Russia is mining. This industry consumes a large amount of energy, but also contributes significantly to GRP. Therefore, despite the results, the sectoral structure of the economy should remain in the focus of the regulator in the energy policy development, primarily due to the significant energy costs inherent in the above mentioned industries. Rather, it should be about the need to supplement the energy intensity of GRP with other indicators of energy efficiency, for example, indicators describing the ratio of energy consumption and energy intensity to the level of regions and countries with similar economic structure and climatic factors, for instance, Canada, Norway, Sweden, etc. The emphasis only on the energy intensity of GRP indicator, together with indicators of certain aspects of energy efficiency (energy efficiency of lighting, energy supply, budget sector, etc.), which is currently made, in particular, in the energy efficiency rating of the Russian regions of the Ministry of energy of the Russian Federation [14], can lead to underestimation of the potential to reduce the energy intensity of industries that are among the most energy-intensive, but are simultaneously highly profitable.

Unfortunately, if the estimated model of the factors affecting the energy intensity of the Russian regions economy explains $69 \%$ of the intra-group variance of the dependent variable in the study, the model of the environmental "cleanness" of the expended energy (Energy / GRP) explains only $8 \%$. In fact, the study did not reveal the factors influencing this indicator in the regions of Russia with an acceptable level of reliability. The possible reasons for the results are the following:

1. Lack of scientific and statistical research on the factors affecting this indicator, and, as a consequence, much less than in the assessment of the energy intensity of GRP, the validity of the hypothesis of the certain factors inclusion in the model.

2. The ratio of pollutant emissions to consumed energy in the regions of Russia is calculated, in contrast to other indicators used in the study, including the energy intensity of GRP and the of pollution intensity of GRP. Some inaccuracies in the assessment of certain official indicators in the methods of Rosstat and the Ministry of natural resources, noted by experts (see, for example, [2]), further reduce the accuracy of estimates in determining the calculated indicators on their basis.

Nevertheless, the study allows us to draw conclusions about the need for further research in order to identify the factors that determine the level of Russian regions in terms of the ratio of emissions of pollutants to consumed energy, since this indicator directly affects the level of environmental efficiency of Russian regions. 


\section{Conclusion}

The study concludes that it is necessary to consider the problems of increasing energy intensity and reducing the pollution intensity as part of the overall problem of strategic sustainability management in the Russian regions. The results confirm the conclusions of experts on the interrelation of the energy, environmental and climate policy objectives in Russia, including the regional level. These objectives should be combined within the framework of the national strategy of sustainable development of Russia. And one of the important sections of this strategy should be the interrelated solution of energy, climate and environmental problems, the evaluation of results by the indicator of regional sustainability.

The results of the study of the factors determining energy and environmental efficiency in the Russian regions allow us to offer important recommendations for policy development in the relevant areas. The most important and global conclusion is the interrelation between the energy and pollution intensity of the regional economy, which determines the need for a coordinated energy and climate policy.

One of the main indicators of energy efficiency of the Russian regions economy is currently the indicator of energy intensity of GRP, as evidenced by the data of the Federal state statistics service, energy strategies and programs, as well as the energy efficiency ratings of the Russian regions developed by the Ministry of energy. However, the study showed that relying only on the energy intensity of GRP can create the impression of good results without real positive changes. This is explained by the fact that the high share of mining industries due to the high profitability allows to achieve low energy intensity at high energy costs. This implies the need to form a system of indicators of energy and climate policy performance in the regions on the basis of their comparison with the results of the best regions and with international best practices.

The results of the study allow us to form recommendations not only for the improvement of regional strategies and programs, but also for the formation of a national system of strategic management of sustainable development of regions, as well as reducing regional inequalities.

The author would like to thank the Russian Foundation for Basic Research for funding this study. The study was carried out with the financial support of the Russian Foundation for Basic Research, the project «Assessment of the strategic sustainability of the enterprises of large, medium and small business in depressive regions of Russia (on the example of the Pskov region)» № 18-010-01204.

\section{References}

[1] Adoption of the Paris Agreement, Framework Convention on Climate Change [Electronic resource]. Available at: http://unfccc.int/resource/docs/2015/cop21/eng/10 9.pdf (Accessed: 20.04.2019).
[2] I. Bashmakov, A. Myshak, Factor analysis of Russian energy efficiency evolution, Voprosy Ekonomiki, 10, 117-131 (2012).

[3] I.S. Belik, N.V. Starodubets, A.I. Yachmeneva, Energy Approach to Measure the Region's Assimilative, Capacity Economy of Region, 4, 13, 1211-1220 (2017). DOI: 10.17059/2017-4-19.

[4] E. De Cian, M. Schymura, E. Verdolini, S. Voigt, Energy Intensity Developments in 40 Major Economies: Structural Change or Technology Improvement, ZEW Discussion Paper 13-052 (2013).

[5] L.V. Eder, I.V. Filimonova, V.Y. Nemov, I.V. Provornaya, Forecasting of Energy and Petroleum Consumption by Motor Transport in the Regions of the Russian Federation, Economy of Region, 3, 13, 859-870 (2017). DOI: 10.17059/2017-3-18.

[6] Energy efficiency in Russia: hidden reserve [Electronic resource]. Available at: http://www.cenef.ru/file/FINAL EE report rus.p df (Accessed: 20.04.2019).

[7] V.P. Kaisarova, V.M. Zhigalov, Socio-economic development of Russia's North-Western regions: evaluation of stability and indices of sustainability, Problems of Modern Economy, 4, 68, 151-157 (2018).

[8] Y.V. Kuznetsov, E.M. Anokhina, N.G. Kizyan, E.V. Melyakova, V.M. Zhigalov, Assessment of the activities of large, medium and small business in the regions of Russia 5th International multidisciplinary scientific conference on social science and arts SGEM, Conference proceedings, 5, 23-26 (3-11 October 2018). DOI: 10.5593/sgemsocialF2018/1.6.

[9] Y.V. Kuznetsov, E.M. Anokhina, E.V. Melyakova, Approaches to Assessing the Performance of Regional, Enterprises in the Russian Federation Economics and Management, 9, 155, 49-59 (2018).

[10] Y.A. Malenkov, Y.V. Kuznetsov, E.M. Anokhina, V.M. Zhigalov, Theoretical and methodological problems of enterprises strategic sustainability evaluation in the depressed regions, The Economic Revival of Russia, 4, 58, 81-88 (2018).

[11] N.V. Pakhomova, K.K. Richter, V.M. Zhigalov, A.S. Malova, Management of Energy-Efficiency in the Context of New Climate Policy Economy of Region, 1, 13, 183-195 (2017). DOI: 10.17059/2017-1-17.

[12] B.N. Porfiryev, Alternative energy as a factor of ecological and energy security: features of Russia Economy of Region, 2, 137-145 (2011).

[13] Y.V. Raskina, The Determinants of CO2 Emissions in the Former Soviet Union: Empirical Analysis Finance and Business, 1, 25-41 (2015).

[14] Rating of energy efficiency of Russian regions, Ministry of natural resources and environment [Electronic resource]. Available at: https://minenergo.gov.ru/node/6533 (Accessed: 20.04.2019). 
[15] A. Rodríguez-Pose, Do Institutions Matter for Regional Development?, Regional Studies, 47, 7, 1034-1047 (2013). DOI: 10.1080/00343404.2012.748978.

[16] State report about environmental condition and protection, Ministry of natural resources and environment [Electronic resource]. Available at: http://www.mnr.gov.ru/docs/o_sostoyanii _i_ob_okhrane_okruzhayushchey_sredy_rossiysk oy_federatsii/gosudarstvennyy_doklad_o_sostoya nii_i_ob_okhrane_okruzhayushchey_sredy_rossiy skoy_federatsii_v_2017_/ (Accessed: 20.04.2019).

[17] V.M. Zhigalov, O.A. Podkorytova, N.V. Pakhomova, A.S. Malova, Interrelation of energy and climate policies: Economic and mathematical justifcation of recommendations for the regulator St Petersburg University, Journal of Economic Studies, 3, 34, 345-368 (2018). DOI: 10.21638/spbu05.2018.301.

[18] V.M. Zhigalov, Strategic role of large business in economy of depressive regions in Russia Current problems of management: management as the most important factor of economic growth and improvement of living standards in the regions, St.-Petersburg, 105-107 (2019). 